\title{
Intrapleural streptokinase: the answer to community acquired pleural infection?
}

\author{
Paul C Deegan, John T Macfarlane
}

Approximately $40 \%$ of patients with community acquired pneumonia develop a parapneumonic effusion, despite the availability of appropriate antibiotics. ${ }^{1}$ This effusion may become secondarily infected, denoted by changes in fluid chemistry (fall in $\mathrm{pH}$ and glucose, rise in $\mathrm{LDH}$ ), organisms on gram staining or culture, and extensive fibrin deposition. Untreated it can result in an empyema with frank pus and fibrous organisation in the pleural space. ${ }^{2}$ Effective treatment requires adequate and early drainage of the fluid. Options include simple aspiration or tube drainage, but these may be hindered by loculation, the formation of fibrinous clots blocking chest drains, and progressive pleural thickening. Thoracotomy with rib resection or decortication achieves the best drainage but carries an associated morbidity and mortality. ${ }^{23}$

Prompt treatment of infected effusions is essential since fibrin deposition can occur within the space of a few days. ${ }^{4}$ However, delays often occur in diagnosis, both in primary care and following admission to hospital. ${ }^{5}$ Thus, patients may present with complicated multiloculated effusions, not amenable to tube drainage alone. Furthermore, the lack of prospective randomised trials has led to controversy over the optimum treatment of infected effusions. ${ }^{167}$

One approach is enzymatic debridement of the pleural cavity with streptokinase, a non-invasive therapeutic option to surgery. Concerns about side effects such as anaphylaxis, intrapleural haemorrhage, and systemic fibrinolysis ${ }^{89}$ have limited its use in the past. However, recent experience with more purified forms of streptokinase has resulted in less anaphylaxis, with significantly reduced haemorrhagic complications using smaller individual doses (250 $000 \mathrm{IU})$ and shorter instillation times (2-4 hours). ${ }^{10}$ The efficacy of streptokinase in promoting drainage of loculated effusions has been suggested by several recent studies, but these involved small patient numbers and were uncontrolled.

In this issue of Thorax Davies et al ${ }^{11}$ report the first prospective randomised trial of early intrapleural streptokinase versus control saline flushes through intercostal drains in patients with an infected parapneumonic effusion or empyema. The streptokinase treated group drained significantly more fluid than the control group, showed significantly greater radiographic improvement, and none needed surgery compared with one quarter of the control group. No clinically significant systemic fibrinolytic effect or haemorrhagic problems were encountered.

An important aspect of this study is that streptokinase was started at the time of diagnosis, rather than at tube drainage failure due to loculation and fibrinous plugging. Patients who fail to respond to treatment with streptokinase already have considerable pleural thickening at surgery. ${ }^{12}$ Thus, if streptokinase is to shorten treatment times and prevent surgery it must be initiated before the fibrinopurulent stage is advanced and organisation occurs.

Placement of the catheter under ultrasound guidance allows better positioning, particularly in multiloculated effusions where it can be placed in the largest loculation. The catheters used by radiologists are frequently much smaller than chest drains traditionally used at the bedside, with improved patient comfort and a more controlled rate of fluid drainage. However, even with the use of radiologically guided placement, suction and saline flushes, the addition of intrapleural streptokinase significantly enhances drainage and reduces the need for surgery. ${ }^{12}$

The findings of Davies et al ${ }^{11}$ allow us to re-evaluate the management of patients with parapneumonic effusions. All patients with suspected pneumonia should be examined clinically and radiologically for the presence of an effusion. Prompt diagnostic thoracocentesis should be performed where fluid is detected. If frankly purulent fluid is obtained, there is direct or indirect laboratory evidence of an infected effusion, or there is loculation on imaging, then a drain should be inserted, preferably under ultrasound guidance. Streptokinase should be administered daily (250 000 IU), even if the effusion is not multiloculated, and continued until the volume drained is $<100 \mathrm{ml} / 24$ hours. Patients should be discussed with a thoracic surgeon and those who fail to respond to this treatment should then be considered for surgical intervention.

Correspondence to: Dr JT Macfarlane.

Respiratory Medicine,

Nottingham City Hospital,

P C DEEGAN

Nottingham NG5 1 PB,

UK

1 Light RW, Girard WM, Jenkinson SG, George RB. Parapneumonic effusions. Am F Med 1980;69:507-11.

2 Kaplan DK. Treatment of empyema thoracis. Thorax 1994;49:845-6.

3 Muskett A, Burton NA, Karwande SV, Collins MP. Management of refractory empyema with early decortication. Am f Surg 1988;156:529-32.

4 Landay MJ, Christensen EE, Bynum LJ, Goodman C. Anaerobic pleural and pulmonary infections. AभR 1980;134:233-40.

5 Ferguson AD, Prescott RJ, Selkon JB, Watson D, Swinburn CR. The clinical course and management of thoracic empyema. $Q \mathcal{F}$ Med 1996;89: 285-9.

6 Sahn SA. Management of complicated parapneumonic effusions. Am Rev Respir Dis 1993;148:813-7.

7 Bouros D, Schiza S, Panagou P, Drositis J, Siafakas N. Role of streptokinase in the treatment of acute loculated parapneumonic pleural effusions and empyema. Thorax 1994;49:852-5.

8 Fraedrich G, Hofmann D, Effenhauser P, Jander R. Instillation of fibrinolytic enzymes in the treatment of pleural empyema. $\mathcal{F}$ Thorac Cardiovasc Surg 1982;30:36-8.

9 Godley PJ, Bell RC. Major haemorrhage following administration of intrapleural streptokinase. Chest 1984;86:486-7.

pleural streptokinase. Chest 1984;86:486-7.
10 Henke CA, Leatherman JW. Intrapleurally administered streptokinase in Henke CA, Leatherman JW. Intrapleurally administered streptokinase in
the treatment of acute loculated nonpurulent parapneumonic effusions. the treatment of acute loculated no
Am Rev Respir Dis 1992;145:680-4.

11 Davies RJO, Traill ZC, Gleeson FV. Randomised controlled trial of intrapleural streptokinase in community acquired pleural infection. Thorax 1997;52:416-2

12 Taylor RFH, Rubens MB, Pearson MC, Barnes NC. Intrapleural streptokinase in the management of empyema. Thorax 1994;49:856-9. 